\title{
Effects of four types of chinese medicines as concomitant drugs with azithromycin for the treatment of mycoplasma pneumonia in children in China: a network meta-analysis
}

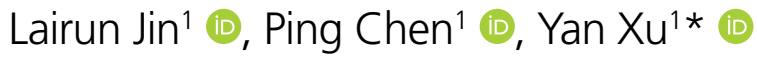

\section{SUMMARY}

OBJECTIVE: The purpose of this study was to evaluate the efficacy of the use of four concomitant Chinese medicines with azithromycin in the treatment of mycoplasma pneumonia in children (MPC) by using network meta-analysis (NMA) and ranking them according to their performances.

METHODS: There were a total of 130 randomly controlled trials of four different concomitant Chinese medicines with azithromycin for the treatment of MPC in many databases, and an NMA was conducted in them by using Stata (version 13.0) software to evaluate the odds ratio (OR) and sequence of the different combinations. The included studies were divided into two groups: control group (azithromycin alone) and observation group (one of four azithromycin combinations).

RESULTS: A total of 13119 cases were included in this study, and the results showed that the pooled OR and 95\% confidence interval (CI) of MPC improvement compared with azithromycin alone were 4.76 (3.18-7.14) for azithromycin and Reduning, 5.66 (4.50-7.12) for azithromycin and Tanreqing, 4.84 (3.35-7.01) for azithromycin and Xiyanping, and 4.58 (3.59-5.83) for azithromycin and Yanhuning, respectively. This study shows the significant efficacy of Chinese concomitant drug. The combination of azithromycin with Tanreqing is the best candidate of concomitant drug in terms of clinical efficacy. Its surface under the cumulative ranking (SUCRA) score was 85.5 , while the SUCRA score for the azithromycin and Yanhuning combination was the worst, which is 48.4 .

CONCLUSIONS: The combination of azithromycin with Tanreqing is the most promising group among four combinations for the treatment of MPC.

KEYWORDS: Network meta-analysis. Azithromycin. Pneumonia, mycoplasma. Randomized controlled trials as topic. Self efficacy.

\section{INTRODUCTION}

Mycoplasma pneumonia in children (MPC) is mild or absent in the early stage, but the disease progresses rapidly, and extrapulmonary complications are diverse ${ }^{1,2}$. The first choice of antibacterial drugs is macrolides, which are represented by azithromycin ${ }^{3,4}$. Due to the long treatment time, the incidence of gastrointestinal symptoms will increase accordingly $y^{5}$. Traditional Chinese medicine has certain advantages in improving efficacy, shortening the course of disease, and reducing toxic and side effects ${ }^{6}$.

Network meta-analysis (NMA) is developed from the traditional meta-analysis, from the standard analysis of two sets of processing factors to a number of different processing factors ${ }^{7}$.

The aim of this study is to evaluate the efficacy of four types of Chinese medicine as concomitant drugs, while azithromycin is administered in the treatment of MPC using NMA,

\footnotetext{
${ }^{1}$ Yijishan Hospital of Wannan Medical College, Office of Educational Administration - Wuhu (Anhui), China.

*Corresponding author: xuyanyjs@126.com

Conflicts of interest: the authors declare there is no conflicts of interest. Funding: none.

Received on September 23, 2020. Accepted on October 04, 2020.
} 
and to rank them according to their performances. These four schemes are most widely used to treat MPC. This includes the combination of azithromycin with Reduning, Tanreqing, Xiyanping, and Yanhuning injections. This study may provide a significantly important guide for the selection of clinical medications for MPC.

\section{METHODS}

\section{Search strategy}

The databases used for this study included Wanfang, China National Knowledge Index, Chongqing VIP Network, China Academic Journal Network Publishing, China Biomedical Medicine, Chinese Science Citation, China Science and Technology Journal, PubMed, Cochrane Library, EMBASE, Web of Science, BIOSIS Previews, SciFinder, and SINOMED. Search strategies were adapted to each database, and they are the variations of the search words, wildcard symbols, and Boolean operators that combine terms. The searching date is from the establishment of the database to February 1, 2020. The search words are as follows: "azithromycin", "combination therapy", "Reduning", "Tanreqing", "Xiyanping", "Yanhuning", "injection”, "efficacy", "pneumonia”, "mycoplasma”, "primary atypical pneumonia", "mycoplasma ovipneumoniae infection", "mycoplasma dispar infection", "children", "child”, "child-mycoplasma pneumonia", and "pediatric pneumonia".

\section{Inclusion and exclusion criteria}

The inclusion criteria were as follows:

1) Randomly controlled trials;

2) Patients who met the requirement of diagnosis of $\mathrm{MPC}^{8}$;

3) Patients aged 14 years and below;

4) The results of the effective number of cases of both the control group and the observation group are provided; and

5) Studies that used azithromycin alone as control group, while the observation group was one of the azithromycin combinations for the treatment of MPC.

The exclusion criteria were as follows:

1) Children with severe dementia or mental illness;

2) Patients with severe tumor, lung, heart, liver or kidney damage, or immune diseases;

3) Purely descriptive studies with no control group;

4) Research types that were reviews, theoretical discussions, summaries of experience, case reports, and animal-based experiments; and

5) Studies with provision of incomplete or repeated data.

\section{Data extraction and quality evaluation}

Two reviewers independently searched the literature and screened all the titles and abstracts of potentially eligible trials based on the inclusion and exclusion criteria, and then, they extracted all the relevant data in each included study. This research extracted the characteristics of participants and interventions, outcomes reported and collected, sample size (control and observation) in each arm, numerical results, and quality indicators of publications. The data extracted were crosschecked, and disagreements were referred to a third reviewer. This study adopts the Jadad quality scoring standard to evaluate the quality of the publications.

\section{Statistical analysis}

This study conducts the network meta-analysis by using Stata software version 13.0 and commands network package. The efficacy of interventions was ranked according to the value of surface under the cumulative ranking (SUCRA) curve. SUCRA values were presented in percentages. The greater the SUCRA value, the better the intervention. The selected indicators were count data, while OR was used as the concomitant effect, and the confidence interval (CI) was set at $95 \%$. The probability value of $\mathrm{p}<0.05$ was defined as statistically significant.

\section{RESULTS}

\section{Characteristics of included studies}

This study identified 130 eligible studies published between 2007 and 2019 eventually. A total of 13119 cases including 6509 control cases and 6610 observation cases were included. Basic classifications of included studies are presented in Table 1.

\section{Network meta-analysis}

\section{Network plot of four types of integrated chinese and western medicines}

Of the 130 publications, the combination of azithromycin with Tanreqing was the most common one, while azithromycin with Reduning was the least frequent one. Figure 1 shows that the azithromycin-alone group had the largest number of subjects, while azithromycin and Reduning had the least number of subjects.

\section{Confidence interval}

The pooled OR and $95 \% \mathrm{CI}$ of MPC improvement compared with azithromycin alone were 4.76 (3.18-7.14) for azithromycin+Reduning, 5.66 (4.50-7.12) for azithromycin+Tanreqing, 4.84 (3.35-7.01) for azithromycin+Xiyanping, 4.58 (3.59-5.83) 
Table 1. Classification of included studies.

\begin{tabular}{|c|c|c|c|c|c|c|c|c|c|}
\hline \multirow[b]{2}{*}{ Comparison } & \multirow[b]{2}{*}{ Year } & \multirow[b]{2}{*}{ Area } & \multirow[b]{2}{*}{$\begin{array}{c}\text { Number of } \\
\text { publications }\end{array}$} & \multicolumn{2}{|c|}{ Observation group } & \multicolumn{2}{|c|}{ Control group } & \multirow[b]{2}{*}{$\begin{array}{c}\text { Duration } \\
\text { (days) }\end{array}$} & \multirow[b]{2}{*}{$\begin{array}{c}\text { Jadad } \\
\text { quality } \\
\text { score }\end{array}$} \\
\hline & & & & $\begin{array}{c}\text { Total } \\
\text { effective } \\
\text { cases }\end{array}$ & $\begin{array}{l}\text { Total } \\
\text { cases }\end{array}$ & $\begin{array}{c}\text { Total } \\
\text { effective } \\
\text { cases }\end{array}$ & $\begin{array}{l}\text { Total } \\
\text { cases }\end{array}$ & & \\
\hline$B$ versus $A$ & 2011-2019 & China & 14 & 667 & 700 & 563 & 698 & $5-21$ & $3-4$ \\
\hline$C$ versus $A$ & 2006-2019 & China & 61 & 2787 & 2887 & 2367 & 2878 & $3-15$ & $2-4$ \\
\hline$D$ versus $A$ & 2011-2019 & China & 18 & 962 & 1002 & 816 & 990 & $4-11$ & $2-4$ \\
\hline E versus $A$ & 2007-2019 & China & 37 & 1929 & 2021 & 1594 & 1943 & $5-10$ & $2-5$ \\
\hline
\end{tabular}

A: azithromycin; B: azithromycin+Reduning; C: azithromycin+Tanreqing; D: azithromycin+Xiyanping; E: azithromycin+Yanhuning.

for azithromycin+Yanhuning, respectively. This study shows a significant difference in efficacy. No significant difference was found in the comparison between azithromycin combinations.

\section{Publication bias}

Figure 2 shows that publication bias may have existed due to the asymmetry in the results of studies.

\section{Ranking of clinical efficacy}

The distribution of probabilities for each treatment is being ranked for their efficacy in MPC according to SUCRA values, and the order of SUCRA values for four types of concomitant Chinese medicine and azithromycin combination is as follows: azithromycin+Tanreqing (85.5), azithromycin+Xiyanping (59.3), azithromycin+Reduning (56.7), and azithromycin+Yanhuning (48.4). As shown earlier, the combination of azithromycin with Tanreqing had the best clinical efficacy.

\section{DISCUSSION}

The network meta-analysis is mainly used to compare the clinical efficacy of three or more interventions ${ }^{9}$. In this study, four types of combined Chinese medicine with azithromycin for treatment of MPC were analyzed. The combinations of azithromycin with Reduning, Tanreqing, Xiyanping, and Yanhuning were more effective when compared to azithromycin alone in the treatment of MPC. The combination of azithromycin with Tanreqing had the highest SUCRA value and probability of being the best treatment option.

Mycoplasma pneumonia in children is a common respiratory disease in pediatrics ${ }^{10}$. After mycoplasma pneumonia (MP) invades the respiratory tract, toxic metabolites, such as hydrogen peroxide, were produced, and antigen structures in the patient's body were changed ${ }^{11-13}$.

Anti-infection therapy is the main clinical practice, and azithromycin is the first choice for the treatment of $\mathrm{MPC}^{14}$. As the third-generation semi-synthetic 15 -membered macrolide antibiotic,

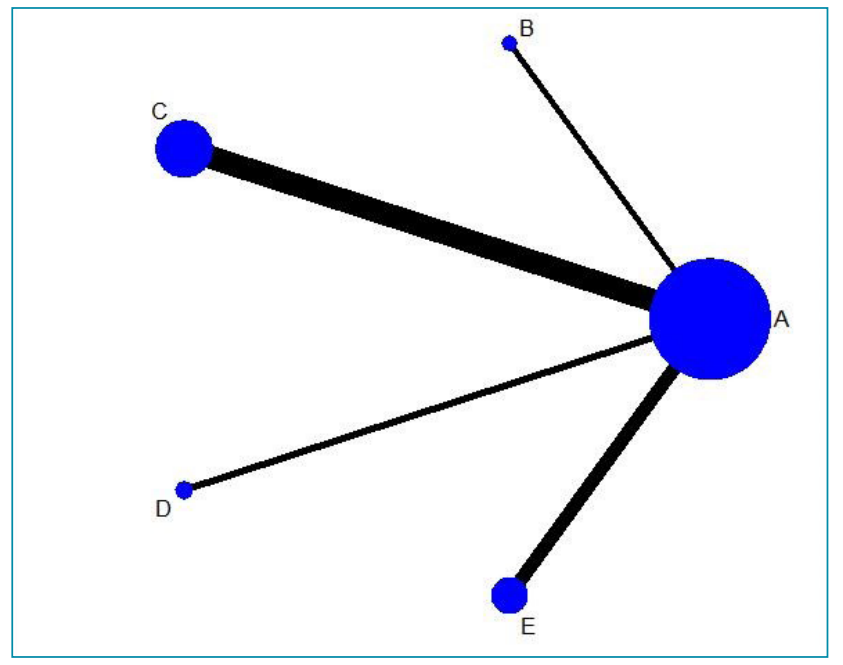

Figure 1. Network plot of different interventions for the treatment of mycoplasma pneumonia in children. The size of the point in the network graph is proportional to the number of subjects, while the thickness of the line is proportional to the number of studies. A: azithromycin; $\mathrm{B}$ : azithromycin+Reduning; $C$ : azithromycin+Tanreqing; $D$ : azithromycin+Xiyanping; E: azithromycin+Yanhuning.

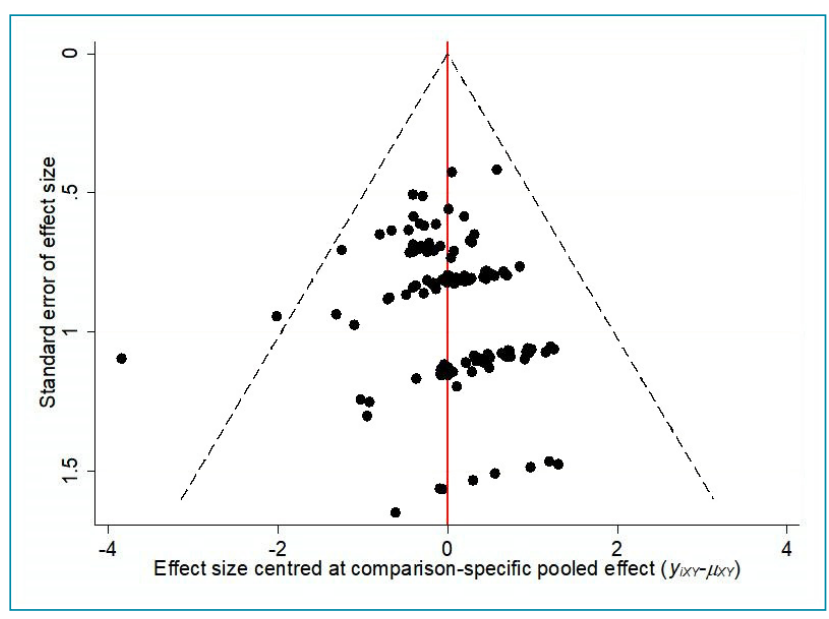

Figure 2. Funnel plot for publication bias in selected studies. 
azithromycin can interfere with the protein synthesis of microorganisms by binding to the $50 \mathrm{~S}$ ribosomal subunit of the microorganism. It has good antibacterial effect on MP and the characteristics of long plasma half-life, strong acid resistance, and strong permeability ${ }^{14}$. However, azithromycin-resistant strains often appear in clinical practice ${ }^{15}$. Exploring effective treatment for MPC has become a difficult task in pediatric clinic. Treatment with azithromycin alone may prolong the course of treatment and increase the risk of infection in other systems of patient ${ }^{16,17}$.

At present, the clinical application of Chinese medicine injection in adjuvant treatment of MPC has achieved good results, showing that traditional Chinese medicine, including Reduning, Tanreqing, Xiyanping, and Yanhuning, combined with azithromycin has significant therapeutic advantages in MPC treatment ${ }^{18}$.

Our findings show that the combination of azithromycin with Tanreqing is the most promising candidate for treatment. Tanreqing injection is a kind of Chinese patent medicine, and its main ingredients include Scutellaria baicalensis, bear bile powder, goat horn, honeysuckle, and forsythia ${ }^{19}$. S. baicalensis, bear bile powder, and goat horn perform the functions of clearing away heat, detoxification, expectorant, and cough suppressant, and they can effectively relieve the symptoms of MPC. Honeysuckle and forsythia have the effect of removing damp heat and enhancing immunity. Due to its advantages of safe application, minor side effects, and resistance to drug resistance, it is selected for clinical use in China ${ }^{20,21}$. This study may provide a guide of great importance for the selection of MPC clinical medications.

\section{CONCLUSIONS}

This study may be very helpful for the clinical treatment of MPC, but there are some limitations in this study. The research examined only the Chinese studies, and there were no consistencies in the treatment dose, duration of treatment in the included publication, and a quantitative analysis of immune system cytokines. Moreover, the result of safety assessment is absent. Therefore, high-quality randomized controlled trials are needed in the future to evaluate the efficacy of the combining traditional Chinese medicine and azithromycin in MPC.

\section{ACKNOWLEDGMENT}

The authors thank Mr. Sheng Zhang from the Department of Hospital-acquired Infection Management, The First Affiliated Hospital, Zhejiang University, for his kind assistance.

Ethical Statement: All analyses were adapted from previous published work. Thus, no ethical approval and patient consent were required.

\section{AUTHORS" CONTRIBUTIONS}

LJ: Conceptualization, Data curation, Formal analysis, Funding acquisition, Investigation, Methodology, Project administration, Resources, Software, Supervision, Writing - original draft. PC: Methodology, Project administration, Resources, Software, Supervision. YX: Validation, Visualization Writing review \& editing. All authors approved the final version of the submitted manuscript.

\section{REFERENCES}

1. You C, Ran G, Wu X, Wang Y, Tian H, Fan J, et al. High immunoglobulin $E$ level is associated with increased readmission in children with bronchopneumonia. Ther Adv Respir Dis. 2019;13:1753466619879832. https://doi. org/10.1177/1753466619879832

2. Sauteur PMM, Unger WWJ, Nadal D, Berger C, Vink C, van Rossum AMC. Infection with and carriage of mycoplasma pneumoniae in children. Front Microbiol. 2016;7:329. https:// doi.org/10.3389/fmicb.2016.00329

3. Lee KY. Pediatric respiratory infections by mycoplasma pneumoniae. Expert Rev Anti Infect Ther. 2008;6(4):509-21. https://doi.org/10.1586/14787210.6.4.509

4. Blyth CC, Gerber JS. Macrolides in children with communityacquired pneumonia: panacea or placebo? J Pediatric Infect Dis Soc. 2018;7(1):71-7. https://doi.org/10.1093/jpids/pix083

5. Yanagihara K, Izumikawa K, Higa F, Tateyama M, Tokimatsu I, Hiramatsu $\mathrm{K}$, et al. Efficacy of azithromycin in the treatment of communityacquired pneumonia, including patients with macrolide-resistant streptococcus pneumoniae infection. Intern Med. 2009;48(7):52735. https://doi.org/10.2169/internalmedicine.48.1482
6. Sun JH, Sun F, Yan B, Li JY, Xin DL. Data mining and systematic pharmacology to reveal the mechanisms of traditional chinese medicine in mycoplasma pneumoniae pneumonia treatment. Biomed Pharmacother. 2020;125:109900. https:// doi.org/10.1016/j.biopha.2020.109900

7. Casadei-Gardini A, Vagheggini A, Gelsomino F, Spallanzani $A$, Ulivi $P$, Orsi $G$, et al. Is there an optimal choice in refractory colorectal cancer? A network meta-analysis. Clin Colorectal Cancer. 2020;19(2):82-90. https://doi.org/10.1016/j. clcc.2019.10.001

8. Waris ME, Toikka P, Saarinen T, Nikkari S, Meurman O, Vainionpää $R$, et al. Diagnosis of mycoplasma pneumoniae pneumonia in children. J Clin Microbiol. 1998;36(11):3155-9. https://doi.org/10.1128/JCM.36.11.3155-3159.1998

9. Best LM, Leung J, Freeman SC, Sutton AJ, Cooper NJ, Milne EJ, et al. Induction immunosuppression in adults undergoing liver transplantation: a network meta-analysis, Cochrane Database Syst Rev. 2020;1(1):CD013203. https:// doi.org/10.1002/14651858.CD013203 
10. Langley A, Anooshiravani N, Kwan S, Zeller J, Pope E. Erythema multiforme in children and mycoplasma pneumoniae aetiology. J Cutan Med Surg. 2016;20(5):453-7. https://doi. org/10.1177/1203475416639018

11. Wang Y, Wang Y, Jiao W, Li J, Quan S, Sun L, et al. Development of loop-mediated isothermal amplification coupled with nanoparticle-based lateral flow biosensor assay for mycoplasma pneumoniae detection. AMB Express. 2019;9(1):196. https:// doi.org/10.1186/s13568-019-0921-3

12. Skapenko A, Leipe J, Lipsky PE, Schulze-Koops H. The role of the T cell in autoimmune inflammation. Arthritis Res Ther. 2005;7 Suppl 2(Suppl 2):S4-14. https://doi.org/10.1186/ $\operatorname{ar} 1703$

13. Billiard F, Litvinova E, Saadoun D, Djelti F, Klatzmann D, Cohen $\mathrm{J}$, et al. Regulatory and effector $T$ cell activation levels are prime determinants of in vivo immune regulation. J Immunol. 2006;177(4):2167-74. https://doi.org/10.4049/ jimmunol.177.4.2167

14. Harris JA, Kolokathis A, Campbell M, Cassell GH, Hammerschlag MR. Safety and efficacy of azithromycin in the treatment of community-acquired pneumonia in children. Pediatr Infect Dis J. 1998;17(10):865-71. https://doi.org/10.1097/00006454199810000-00004

15. Hooda Y, Sajib MSI, Rahman H, Luby SP, Bondy-Denomy J, Santosham M, et al. Molecular mechanism of azithromycin resistance among typhoidal salmonella strains in Bangladesh identified through passive pediatric surveillance. PLoS Negl Trop Dis. 2019;13(11):e0007868. https://doi.org/0.1371/ journal.pntd.0007868
16. Durukan D, Read TRH, Murray G, Doyle M, Chow EPF, Vodstrcil LA, et al. Resistance-guided antimicrobial therapy using doxycyclinemoxifloxacin and doxycycline- $2.5 \mathrm{~g}$ azithromycin for the treatment of mycoplasma genitalium infection: efficacy and tolerability. Clin Infect Dis. 2020;71(6):1461-8. https://doi.org/10.1093/cid/ciz1031

17. Harrison MA, Harding-Esch EM, Marks M, Pond MJ, Butcher $\mathrm{R}$, Solomon AW, et al. Impact of mass drug administration of azithromycin for trachoma elimination on prevalence and azithromycin resistance of genital mycoplasma genitalium infection. Sex Transm Infect. 2019;95(7):522-8. https://doi. org/10.1136/sextrans-2018-053938

18. Pan GY, Ma R, Zhang $X L$, Sun $H$, Yan HH, Rong P. Network meta-analysis of effect of traditional chinese medicine injections in adjuvant treatment of mycoplasma pneumonia in children. Zhongguo Zhong Yao Za Zhi. 2020;45(2):425-35. https://doi. org/10.19540/j.cnki.cjcmm.20190826.501

19. Li XX, Zhuo L, Zhang Y, Yang YH, Zhang H, Zhan SY, et al. The incidence and risk factors for adverse drug reactions related to tanreqing injection: a large population-based study in China. Front Pharmacol. 2020;10:1523. https://doi.org/10.3389/ fphar.2019.01523

20. Liu W, Zhang X, Mao B, Jiang H. Systems pharmacology-based study of tanreqing injection in airway mucus hypersecretion. J Ethnopharmacol. 2020;249:112425. https://doi.org/10.1016/j. jep.2019.112425

21. Liu DJ, Zheng B, Cai BH, Zhou WM, Yu BX. Traditional chinese and western medicine treatment of mycoplasmal pneumonia in children and the serum cytokine changes. Nan Fang Yi Ke Da Xue Xue Bao. 2020;30(3):626-7, 630. PMID: 20335158 